\title{
Burned out
}

Shaun Sellars continues his series on ethical dilemmas in dentistry which appears in every second issue of the $B D J$.

You're tired, always tired. Exhausted.

That niggle that you've been ignoring for the last few months has now turned into constant pain. You're not getting enough sleep. The coffee gets stronger and stronger. The occasional glass of wine has turned into the regular bottle.

You're not feeling well enough to go to work. Your cold is lingering, but Mrs Jones has been waiting for her appointment for two months, and you wouldn't be able to squeeze her in again this side of Christmas. And besides, the mortgage won't pay for itself.

All around you are people with more. Bigger. Better. Faster. Meanwhile, your car has just broken down and you're not sure how you're going to pay for it. If you can just sell more crowns. Do more whitening. How can you fit that in when you have your targets? UDA. KPI. Profitability.

Maybe this course will change everything?

It won't, of course. But the never-ending chase to reach the next level will continue until you collapse. By then it may be too late.
We're so busy looking after other people that sometimes we can forget to look after ourselves. Burnout is a real risk for many of us. The associated drop in performance or apathy towards our jobs may lead to mistakes. Increasing stress. Accelerating that burnout.

As a profession, we need to learn to look after each other. Dentistry can be insular, often with minimal social interaction outside the four walls of the surgery. This combined with the competitive nature of local businesses and the increasing shadow of corporate structures with associated targets driving performance, the world of dentistry seems tailor-made to encourage burnout.

I'd venture to guess that every one of us could use some form of support at any one stage of our careers. Like other mental health issues, there has been limited real practical help for those in need. Newly graduated practitioners are particularly at risk, often being dropped in at the deep end, to a system of UDAs which they're unprepared for, with a skill set that requires careful nurturing and development. This system has to change. Dentistry has to react to this unspoken crisis. The

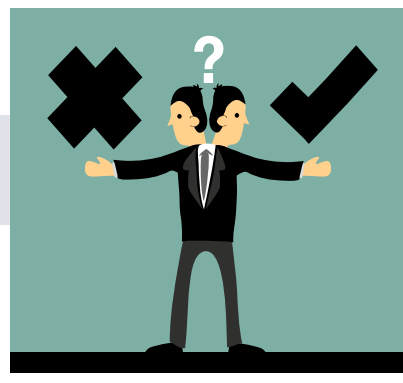

dental profession has long been associated with a high risk of suicide. We cannot ignore the elephant in the room any longer.

In the past help has been almost non-existent, but recently there has been a turnaround. The Facebook Group 'Mental Dental - A Group For Dentists in Crisis' has been pivotal in raising awareness of current mental health issues in the profession. This has recently been joined by services including the BDA's own 'Health Assured' helpline which aims to help with a wide range of issues.

Through this, it must be remembered that in order to put patients' interests first, you have to be in a fit state to practise dentistry. You can't look after patients if you can't look after yourself. And in order to look after ourselves, we'll need to look out for each other. Learn to recognise the signs that someone may be struggling. Those in the midst of burnout often don't realise until it's too late. Reach out. Support your colleagues.

\section{Help deliver Christmas cheer}

The BDA Benevolent Fund helps dental students, dentists and their families when they face hardship, supporting those who do not have the funds to pay for some of the normal things in life, ranging from contributions towards food and daily living costs, funds to improve the quality of life for those retired due to ill health, to more specific needs like paying someone's annual retention fee or indemnity, to help them get back on their feet and into the profession.

The impact of the relatively small but incredibly caring and generous group that makes up the dental profession cannot be overstated. There are many stories out there that evoke a feeling of sadness but, working together, lives can genuinely be changed for the better on an ongoing basis.

Between October and the end of the year, the team at the BDA Benevolent Fund will be doing all they can to keep a roof over people's heads, as well as fed, safe and warm.

They will also give people additional support so that they can feel a sense of normalcy, for example ensuring the children of beneficiaries do not miss out on a present, or that no-one spends Christmas Day alone because they cannot afford to travel to their family.

If you, or someone you know are in need, please contact the BDA Benevolent Fund straight away. If you're worried about your reputation (although there is obviously no shame in needing help), everything is confidential - simply call 02074864994.

If you are able to make a donation, please visit https://uk.virginmoneygiving.com/charity-web/charity/finalCharityHomepage. action? charityId $=1014657$ or send cheques payable to 'BDA

Benevolent Fund' to BDA Benevolent Fund, 64 Wimpole Street, London W1G 8YS.

For more information, visit www.bdabenevolentfund.org.uk. 